\title{
Primer of Ecological Restoration
}

By Karen D. Holl. 2020. Island Press. 224 pages, 35.00 USD, Paper or E-book.

Primer of Ecological Restoration is a textbook-style book written by the wellpublished primary researcher Dr. Karen Holl. The author's stated goal is to create a broad but succinct introductory text that would be useful as a textbook for restoration ecology courses where more detailed case readings are assigned in tandem, one of several resourc-

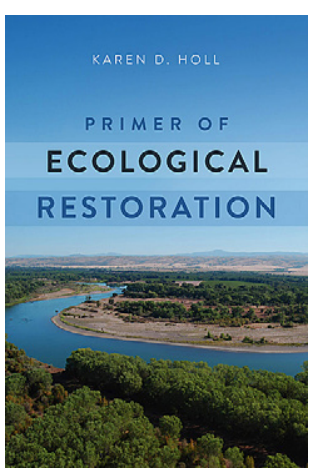
es for a conservation biology or resource management course, or as an introduction to the field of restoration for resource managers or a general audience.

In the Preface, Holl is very clear about what the book is not-it is not an in-depth comprehensive guide nor a "how to" for restoring particular ecosystem types. As you would expect from a primer, this book provides more breadth than depth. That being said, it introduces the principal questions, debates, and complexity that characterize the discipline. As a primer it largely meets its stated goals: the glossary is excellent, it boasts a clearly cited references section, and the index is intuitive and well executed. Each of the short chapters (6-19 pages) ends with an annotated "recommended reading" list of a few additional sources, with a brief sentence from Holl describing their content.

While Holl achieves the goal of creating an introductory text chock full of jumping off points, there are certain areas where more direction would be helpful. Several controversial topics in the discipline that would have benefitted from more depth include novel ecosystems, conflicting restoration goals (specifically strategies on how to resolve them, or examples of success), and anticipatory/climate shifted restoration. Similarly, Traditional Ecological Knowledge (TEK) and collaborations with First Nations stakeholders receive two brief mentions; the book would benefit from addressing these topics in a more deliberate way and providing additional resources as it does so effectively for other topics.

Appropriate emphasis is placed on the need for long-term planning, monitoring, and clear, actionable goals - all significant and common stumbling blocks for successful restoration initiatives. Much of the book is prescriptive-what should be considered. What is sometimes lacking, however, is the "how"- provisioning budget and personnel for long-term monitoring is important, yes, but successful examples to follow are not provided. Chapters 6 (Landform Hydrology), 7 (Soil and Water), 8 (Invasive Species), 9 (Revegetation), and 10 (Fauna) are the most fleshed out, providing various examples and specifics of successful interventions and techniques. Chapter 6 is particularly detailed, with several excellent supporting diagrams to explain major concepts. Holl's definitions of invasive and non-native species used in Chapter 8 (Invasive Species) are one of the few elements in the text that are both controversial and uncited-considering the widespread and ongoing debate on this topic, not every reader will agree with the resulting recommendations of the chapter. The book may also have benefitted from a short conclusion section; the text's final topic-based chapter ends with the glossary on the facing page.

To keep costs low, the author has chosen to use primarily diagrams and tables; colour photos are instead included in the accompanying materials on the Island Press website. The diagrams included in the text are well chosen, especially those explaining key spatial concepts (e.g., habitat connectivity, soil layers). The accompanying resources at https:// islandpress.org/restoration-primer include short case studies mentioned in the text (downloadable PDFs, one per case study), downloadable PowerPoint slides with high resolution copies of figures used in the text, discussion and reflection questions for each chapter, and a document listing additional resources (videos, books, example restoration plans, and websites). Although not necessarily of interest to a casual reader, these resources are good quality and valuable for instructors looking to use this text as a learning tool.

Overall, this book is a successfully executed primer that meets its stated goals admirably for such a short text. Combined with the online resources, it is likely most useful for instructors who assign additional readings to expand on different concepts pertinent to their courses. As it is well written and generally free of jargon (and fashioned with an excellent glossary), the primer would also be a valuable introduction for junior practitioners or interested members of the public. If you are new to ecological restoration, this is a solid introductory text.

Heather A. CRAY Halifax, NS, Canada

(C) The author. This work is freely available under the Creative Commons Attribution 4.0 International license (CC BY 4.0). 